\title{
MODELING OF TIIE OPEN-DIE AND RADIAL FORGING PROCESSES FOR ALLOY 718
}

\author{
Christina Boyko', Hani Henein ${ }^{1}$, F. Robert Dax ${ }^{2}$ \\ ${ }^{1}$ Department of Mining, Metallurgical, and Petroleum Engineering, \\ 606 Chemical-Mineral Building, University of Alberta, \\ Edmonton, Alberta, CANADA, T6G-2G6, \\ ${ }^{2}$ Cytemp Powder Products, Mayer Street, Bridgeville, $\mathrm{Pa}, 15017$
}

\begin{abstract}
$\underline{\text { Abstract }}$
To better understand the effects of process parameters on the production of a finc-graincd forged 718 billet, and to assist Cytemp in the selection of a new forging machine, a detailed modeling effort was conducted on the processing of 718 . The specification of appropriate boundary conditions and material data, and the formulation of the finite element models using DEFORM are discussed. The modeling results revealed, in a qualitative way, that open die forging tends to do more work at the center of the ingot, while radial forging brings about more deformation at the ingot surface. Die shape was identified as an important forging design variable. Curvature at the corners of the die, compared with curvature at the center of the die, rcsulted in more work at the center of the ingot. Better penctration of work to the center of the ingot also resulted from increasing bite ratios to as high as 0.8 in radial forging. Many of the variables considered had a concomitant effect on the curvature of the end of the ingot. This latter parameter could be used for verification in plant trials, where the kinematic boundary conditions could be carefully monitored. Forging operators and consultants verified that the results reported in this study are qualitatively correct in predicting trends in open-die and radial forging operations.
\end{abstract}

Superalloys 718, 625 and Various Derivatives

Edited by Edward A. Loria

The Minerals, Metals \& Materials Society, 1991 


\section{Introduction}

The manufacturing requirements for forging Alloy 718 billets are to economically meet quality criteria for alloy chemistry, product shape, and product microstructure. Thus, a good knowledge is required of the relationship between forging parameters and product quality, as well as of the optimum operating strategy for processing a number of billets simultaneously. The objective of this project was to develop this enabling technology for open die and radial forging of Alloy 718. As illustrated in Figure 1, the approach used involved a number of key tasks.

The first task, modeling of forging shedules for each billet (Forging Practice Design in Figure 1), was accomplished using COMFORGE. ${ }^{1}$ The second task was the development of a heat flow model of the reheating of 718 billets. This model was to provide, in real time, a solution for the temperature profile in a billet at any time during the processing sequence. The third task of this study was the development of an intelligent sequencer: one that would be used by the operator to assist in achieving the manufacturing requirements for the 718 product under optimum process conditions. Finally, the fourth task dealt with the development of a microstructure-process model to infer the billet microstructure, given the forging process parameters. This was addressed in two stages, the first was the forging process model, the subject of this paper, and the second was the determination of the billet microstructure given the process model results. The implementation of these tasks forms the elements of an Intelligent Manufacturing Cell for operating a forging facility and for providing a stand-alone tool that can be used in the development of forging practices as well as other day-to-day engineering and technical requirements. ${ }^{2}$ This paper will focus mainly on finite element modeling of the forging process.

The development of a forging model requires a good understanding of the process and of the process variables manipulated to arrive at a finished product with the desired quality. Thus, the boundary conditions of the forging operation need to be determined, and the forging process must be modeled. The process modeling tasks of this project were divided into numerical modeling and forging trials. The numerical models were formulated using DEFORM. ${ }^{3}$ Open die and radial forging processes were examined by analysing the effects of varying boundary conditions and operating parameters. This effort not only provided Cytemp with a better understanding of the production of superalloy material, but also provided insight into the capabilities of different forging machines. In order to accurately model a process, the correct boundary conditions (such as interface heat transfer coefficients and friction factors) and material property data must be used. This information was obtained both from the literature and from tests performed at Wright State University and Wright Patterson Air Force Base. A summary of some of the important input parameters will be given in this paper. Although the plant trials for radial forging were not completed as of the writing of this paper, the model results were verified qualitatively using plant practice and operating experience.

\section{Boundary Conditions}

The modeling of forging processes is necessary to reduce both lead time and trial and error. Numerical modeling of forging is frequently done using a finite element rigid viscoplastic program, such as DEFORM. The use of DEFORM requires the forging database for the die and workpiece materials. This includes the flow stress as a function of temperature, strain rate, and strain; the friction factor between the die and workpiece; and the contact heat transfer coefficient for the die and workpiece combination. Versions 1.1 and 1.2 of DEFORM were used 
in the work discussed here.

\section{$\underline{\text { Heat Transfer Coefficient }}$}

The methodology for, and importance of, determining interface heat transfer coefficients which are relevant to deformation processing has been well established and delineated in the literature. ${ }^{4}$

Interface heat transfer coefficient measurements were conducted by Dr. Vinod Jain at WrightPatterson Materials Lab. ${ }^{5}$ The range of test variables which are relevant to the forging process for Alloy 718 are summarized here. The workpiece specimens were heated to $982^{\circ} \mathrm{C}\left(1800^{\circ} \mathrm{F}\right)$, $1037^{\circ} \mathrm{C}\left(1900^{\circ} \mathrm{F}\right)$, and $1093^{\circ} \mathrm{C}\left(2000^{\circ} \mathrm{F}\right)$; the Waspaloy dies were heated to $316^{\circ} \mathrm{C}\left(600^{\circ} \mathrm{F}\right)$. At each temperature, 8 to 10 data points were taken over a range of pressures up to $138 \mathrm{MPa}$ ( 20 kpsi). Figure 2 shows sample regression results for the change in interface heat transfer coefficient (IHTC) with pressure and temperature. Interface heat transfer coefficient data can be used by DEFORM as a constant value or in tabular form, given values of IHTC as a function of time or pressure. Unfortunately, DEFORM 1.1 and 1.2 are not able to interpolate among heat transfer coefficient versus pressure curves for different temperatures. Furthermore, the experimental data used to derive the regressed curves in Figure 2 had considerable scatter, and, as such, the change in the heat transfer coefficient-pressure relationship for varying temperature cannot be delineated accurately.

\section{$\underline{\text { Ring Tests - Friction Factor (m) }}$}

Knowledge of friction is important to the modeling and analysis of forging processes for quality forged parts in a timely and cost-effective manner. Friction between die and workpiece influences the metal flow within the deformation zone, and thus influences the energy requirements and press forces.

Boundary lubrication, which is the type most commonly encountered in metal forming, is difficult to analyze. ${ }^{6}$

The ring compression test has proven very useful and gained wide acceptance in predicting the friction factor under various temperature, lubrication, strain rate, and strain conditions. The test consists of compressing a flat, ring shaped specimen to a known reduction between two flat dies. As the height is reduced, the ring expands outward radially. If friction at the interface is zero, both the inner and outer diameters expand as if the ring were a solid disk. With increasing friction, the rate of increase of the inner diameter decreases. For any particular reduction in height there is a critical value of friction factor $m$, whereby the inner diameter increases (from the original) if $\mathrm{m}$ is low and decreases if $\mathrm{m}$ is large.

Nonisothermal ring calibration curves for the determination of the shear friction factor between Alloy 718 and Waspaloy for a variety of test temperatures and conditions were provided. ${ }^{5}$ The starting materials for the ring tests were as-cast Alloy 718 (with grain sizes ranging from 0 to 3 ) and intermediate-forged 718 (with grain sizes ranging from 6 to 8). The grain sizes of the compressed rings ranged from 0 to 3 . By comparing the inner diameters of the compressed rings with the information provided on the calibration curves, the applicable friction factors could be determined. For much of the work performed, it was found that shear friction factors in the range of 0.2 to 0.4 were appropriate. The friction factor may be input into DEFORM as a constant value or as function of time or of pressure in tabular form. The former approach was used in the simulations discussed in this paper. 


\section{Compression Test Simulations}

Compression test were performed by Dr. Raghu Srinivasan at Wright State University ${ }^{7}$ and by SMS Hasenclever in Dusseldorf, West Germany. ${ }^{8}$ A variety of temperatures (ranging from $775^{\circ} \mathrm{C}\left(1427^{\circ} \mathrm{F}\right)$ to $1200^{\circ} \mathrm{C}\left(2192^{\circ} \mathrm{F}\right)$ ) and a variety of strain rates (ranging from $-0.001 \mathrm{~s}^{-1}$ to $-1.0 \mathrm{~s}^{-1}$ ) were considered. Some of the tests were performed on material having an as-cast microstructurc, some on matcrial having a finer grain structure. The samples were compressed to a true strain of -0.693 (50\% reduction in height). The objective of compression testing was to develop a database of flow stress relationships for Alloy 718 for a variety of starting microstructures. The test conditions for the compression tests are listed in Table 1. For Series CY $\Lambda$ and CYC, the initial sample size was $13 \mathrm{~mm}(0.5$ inches $)$ diameter by $19 \mathrm{~mm}(0.75$ inches) high; for step one of Series CYB, the initial sample size was $25 \mathrm{~mm}$ ( 1 inch) diameter by $38 \mathrm{~mm}$ ( 1.5 inches) high; for step 2 of Series CYB, the initial sample size was $13 \mathrm{~mm}(0.5$ inches) diameter by $19 \mathrm{~mm}$ ( 0.75 inches) high. The Waspaloy dies were $51 \mathrm{~mm}$ ( 2 inches) in diameter and $13 \mathrm{~mm}$ ( 0.5 inches) high. For the SMS compression tests, the initial sample size was $20 \mathrm{~mm}$ diameter by $30 \mathrm{~mm}$ high.

Table 1: Starting grain sizes and test conditions for compression tests.

\begin{tabular}{|c|l|l||}
\hline Series & \multicolumn{1}{|c|}{ Grain Size at Start } & \multicolumn{1}{|c|}{ Test Conditions } \\
\hline CYA & $\begin{array}{l}\text { As cast: G.S. }>>00 \\
\text { (elongated grains) }\end{array}$ & $\begin{array}{l}\mathrm{T}=950^{\circ} \mathrm{C} \text { to } 1125^{\circ} \mathrm{C} \\
\dot{\varepsilon}=-0.01 \text { to }-1.0 \mathrm{~s}^{-1}\end{array}$ \\
\hline CYB & $\begin{array}{l}\text { Step 1: As cast: G.S. }>>00 \\
\text { Step 2: Product of step 1 } \\
\text { Step 3: Product of step 2 }\end{array}$ & $\begin{array}{l}\mathrm{T}=950^{\circ} \mathrm{C} \text { to } 1050^{\circ} \mathrm{C} \\
\dot{\varepsilon}=-0.035 \text { to }-0.35 \mathrm{~s}^{-1}\end{array}$ \\
\hline CYC & G.S. 5 to 8 & $\begin{array}{l}\mathrm{T}=875^{\circ} \mathrm{C} \text { to } 1000^{\circ} \mathrm{C} \\
\dot{\varepsilon}=-0.0035 \text { to }-0.35 \mathrm{~s}^{-1}\end{array}$ \\
\hline Fine Grained & G.S. 6 to 8 & $\begin{array}{l}\mathrm{T}=1038^{\circ} \mathrm{C} \text { to } 1177^{\circ} \mathrm{C} \\
\dot{\varepsilon}=-0.001 \text { to }-1.0 \mathrm{~s}^{-1}\end{array}$ \\
\hline SMS & G.S. 6 & $\begin{array}{l}\mathrm{T}=800^{\circ} \mathrm{C} \text { to } 1200^{\circ} \mathrm{C} \\
\dot{\varepsilon}=-0.1 \text { to }-1.0 \mathrm{~s}^{-1}\end{array}$ \\
\hline
\end{tabular}

The CYB series of tests comprised three steps. The first step involved compression of specimens having a coarse, as-cast grain structure. New specimens were machined from the compressed samples to provide the samples for the second step. Similarly, the samples were remachined after the second step to provide samples for a third step. These tests were intended to investigate the effects of prior defurmation on deformation behavior. The agreement between uncorrected flow stress values for Series A and the first step of Series B was not good. This may be a consequence of the elongated nature of the as-cast grains.

Data from The CYC series of compression tests was used to determine the strain rate sensitivity as a function of temperature and strain rate for strains of -0.15 and -0.35 . The compression test results on fine-grained Alloy 718 were used to extend the range of variables for strain rates and temperatures. The results of the compression tests provided the constitutive behavior of Alloy 718 for a variety of strain rates and temperatures. The flow stress data was input into DEFORM in tabular form. 


\section{Model Formulation}

Both open die and radial forging simulations were performed. Owing to the fact that DEFORM is limited to plane strain and axisymmetric geometries, only transverse or longitudinal sections of the ingot could be modeled. In the case of open die forging, plane strain simulations were used both for transverse and longitudinal sections. In the case of radial forging, plane strain was assumed for transverse sections, while the axisymmetric case applied to longitudinal sections. This information is summarized in the table below.

Table 2: Test matrix for DEFORM simulations.

\begin{tabular}{|c|c|c|}
\hline & Transverse Section & Longitudinal Section \\
\hline Open Die Forging & Plane Strain & Plane Strain \\
\hline Radial Forging & Plane Strain & Axisymmetric \\
\hline
\end{tabular}

\section{Transverse Sections}

Plane strain simulations were used to analyse transverse sections of an ingot in both open dic and radial forging. Longitudinal end effects could not be addressed with such sections. It was also found that DEFORM's inherent assumption of volume conservation (which becomes area conservation in 2D) limited the stroke in radial forging simulations. Area conservation also precluded modeling of consecutive bites or passes for both open die and radial forging. The utility of plane strain simulations on transverse sections was that the results could provide a qualitative understanding of the regions of the ingot which were most highly worked.

\section{$\underline{\text { Longitudinal Sections }}$}

$\Lambda$ major consequence of open die and radial forging is axial elongation of the ingot. This phenomenon cannot be addressed in plane strain simulations using transverse sections. A plane strain simulation of open die forging using a longitudinal section represents a compromise between physical reality and the capabilities of 2D DEFORM. The simulation scenario actually represents a section through an infinite slab of rectangular cross section. It is assumed that the results for such a section bear some qualitative relation to those which would obtain in a section through the centerline of a cylindrical ingot.

By contrast, radial forging can be modeled by an axisymmetric simulation using a longitudinal section of an ingot. This geometric representation of the ingot is quite realistic. However, the dies cannot be modeled as four discrete entities, but rather as a single ring-shaped die.

Apart from deficiencies regarding the physical representation of the ingot (open die forging) and the dies (radial forging), models of longitudinal sections can be used to study axial elongation of the ingot for successive bites and passes. As well, different dies, bite ratios, and end boundary conditions can be studied with models of longitudinal sections. Of particular value is information about the portions of the ingot which are most highly worked and about the change in shape of the end of the ingot with varying process variables. 


\section{Modeling Variables}

Both for open die and radial forging simulations, it was necessary to consider basic aspects of finite element modeling, such as the step increment, the optimal discretization of the finite element mesh, the required mesh size of a "representative" section of the workpiece, and the specification of the boundary conditions on the domain of the solution. For the simulations discussed herein, the step size was taken to be $1 \%$ of the total stroke. In their comparative study of the ALPID and MARC codes, Jay et al. found that a step size of 2pcrcent-per-increment provided dependable solutions. ${ }^{9}$ Thus, a 1-percent-per-increment step size, despite costing additional CPU time compared with a 2-percent-per-increment step size, should be sufficient. The other variables are discussed briefly, below.

It should also be noted that symmetry was utilized, wherever possible, to reduce the size of the problem. In transverse section simulations, one quarter of the cross section of the ingot was usually sufficient (unless the interobject boundary conditions between the upper die and the workpiece and between the lower die and the workpiece differed); in longitudinal section simulations, one half of the cross section of the ingot was modeled.

\section{$\underline{\text { Mesh Discretization }}$}

A given simulation was first performed using a coarse mesh; the size of the elements was decreased until convergence of the solution was obtained. Transverse sections were of correspondingly lower cross-sectional area than longitudinal sections; thus, smaller elements could be used. Typically, the element size was in the range of $6.4 \mathrm{~mm}(0.25$ inches $)$ to $13 \mathrm{~mm}$ ( 0.50 inches). $19 \mathrm{~mm}$ ( 0.75 inch) squares were found to be convenient in terms of balancing quality of results and CPU times for most of the simulations on longitudinal sections of the ingot; a uniform grid was satisfactory for isothermal simulations. For nonisothermal simulations, such as the realistic simulation of the first bite of the first pass of a prescribed forging sequence, nonuniform mesh discretization was often employed. For example, see Figure 3, where the element size ranges from $13 \mathrm{~mm}(0.5 \mathrm{inch})$ squares to $51 \mathrm{~mm}(2 \mathrm{inch})$ squares.

Remeshing was required whenever the degree of distortion of the original mesh became great enough to cause negative Jacobians. The preprocessing module of DEFORM allows for manual remeshing at any step stored within the simulation database. DEFORM's mesh generator allows the user to specify the desired mesh density (number of elements per millimetre) throughout the domain of the solution at the start of the simulation and during remeshing steps.

\section{Ingot Length}

A short $(0.53 \mathrm{~m})$ ingot was originally chosen in conjunction with the use of a $0.18 \mathrm{~m}(7 \mathrm{inch})$ long die. It was thought that an ingot length of three times the length of the die would be sufficient to enable the analysis of a number of consecutive bites before encountering end effects. An ingot length of $0.53 \mathrm{~m}$ (21 inches) was suitable, in terms of keeping CPU times reasonable, for running sensitivity analyses on longitudinal sections. However, the short length of the ingot thereby limited the number of bites per pass which could be modeled. Also, a very short ingot makes it difficult to study the effects of large bite ratios over a number of bites. For some simulations, a full ingot length was used. The ingot shown in Figure 3, for example, is $1.8 \mathrm{~m}$ (72 inches) long. The first bite of the first pass of a nonisothermal simulation using this model took 8.2 CPU hours on a DEC Vaxstation 3500 operating under VMS 5.1. 


\section{Boundary Conditions at Free End of Ingot}

Deformation of the ingot in the vicinity of the die was sensitive to the kinematic boundary condition at the end of the ingot further from the die. In plant operations, neither a fully-fixed nor a fully-free condition is satisfactory; however, both extremes were modeled to provide benchmark solutions. The nature of the boundary condition at the end of the ingot may be discerned in the longitudinal simulation results, following, by noting the coordinates of the undeformed end of the ingot. If the axial coordinate of the undeformed end of the ingot is zero, a fully-fixed boundary condition was employed (Figure 4), whereas a negative axial coordinate at the end of the ingot (Figure 5) indicates a fully-free boundary condition. Carefully monitored plant trials are necessary to determine realistic boundary conditions.

\section{Results and Verification}

\section{$\underline{\text { Penetration of Work }}$}

The DEFORM simulation results revealed that work is done preferentially near the surface of the ingot in radial forging and near the center of the ingot in open die forging, Figure 6 . The measure of work done is the level of effective strain in the ingot. Penetration of work in the ingot has been assessed, in practice, by looking at the recrystallized grain structure and flow: lines of actual ingots and also by observing the grid lines on wax and plastecine models of ingots. The finite element model results agree both with observations of actual forging operations ${ }^{10}$ and with physical modeling.

Modification of die geometry has been used to investigate the penetration of work in the ingot. Ideally, it would be beneficial to effect more work in the outside of the ingot in open die forging and to cause the work to penetrate the ingot more deeply in radial forging. A predominantly flat die with a dimpled surface has been shown to be of benefit in working the surface of the ingot in open die forging. ${ }^{11}$

In general, except where the dies could be represented by line segments (isothermal simulations) or squares (nonisothermal simulations), two die shapes were employed in radial forging simulations in the present work. The first was a square die with rounded corners $(25.4$ $\mathrm{mm}$ ( 1 inch) radius of curvature); the second was a die having a flat portion in the middle and angled sections to either side of the flat portion. See Figures 4.a. and 4.b, respectively. Note that the square die with rounded corners imparts more work into the ingot beneath the die after the first bite of the first pass compared with the faceted die. An exhaustive study is required to generalize the result and to optimize die shape.

\section{Friction Factor and Bite Ratio}

The results of simulations using transverse sections of an ingot were not very sensitive to changing friction factor. Perhaps this is a reflection of the high degree of physical constraint built into such simulations, by virtue of the geometry and the boundary conditions.

Figures 5 and 7 show both effects of friction factor and bite ratio on effective strain contours for simulations on longitudinal sections. Bite ratio may be defined as the overlap, at the start of a bite, of the die on the ingot, divided by the half depth of the workpiece. When dies with rounded corners are used, the radius of curvature of the die is sometimes subtracted from the 
overlap. ${ }^{8}$ In Figure 7, effective strain contours are shown for three successive bites of the second pass of radial forging. A low bite ratio (0.24) was used in these simulations; the results were not sensitive to a change from a friction factor of 0.3 to 0.8 . Figure 5 shows effective strain contours after the second bite of the first pass of radial forging using a bite ratio of 0.67 . It is seen that the isostrain contour labeled " $\mathrm{C}$ " (near the center of the ingot, to the left fo the die) covers a larger region for a friction factor of 0.8 compared with a friction factor of 0.3 .

Small bite ratios were investigated using short $(0.18 \mathrm{~m}(7 \mathrm{inch}))$ dies in isothermal simulations of open die forging using longitudinal sections of the ingot. Surface flaws (such as laps), as shown in Figure 8, occurred over a range of bite ratios, ranging from 0.36 to 0.6. Figure 8 shows the shape of the deformed workpiece after the third bite of the second pass.

From physical modeling studis of open die forging, ${ }^{8}$ it was suggested that the use of bite ratios larger than about 0.5 to 0.6 could eliminate the excessive curvature at the end of the ingot nearest the die in the radial forging simulations on longitudinal sections. It was also suggested that this range of bite ratio could result in more work being done in the center of the ingot. Additional simulations were run to investigate larger die sizes (from $0.25 \mathrm{~m}$ (10 inches) to 0.36 $\mathrm{m}$ (14 inches)) and bite ratios ranging from 0.5 to 0.8 , Figure 9. Larger bite ratios decreased the curvature of the end of the ingot nearer to the die. (The end became markedly less sigmoidal as bite ratio increased.) Furthermore, the larger bite ratios resulted in more work being done in the center of the ingot. However, the optimum ratio of 0.5 to 0.6 , observed in open die forging, was not borne out by these simulations on radial forging.

\section{Temperature Gradients}

Another result demonstrated by the simulations is that surface cooling of the ingot increases the penetration of work into the ingot. A cooler surface, having a higher flow stress than the core of the ingot, acts, in effect, as an extension of the die. It can be seen from DEFORM results (Figure 10) that larger dies increase the volume of material worked by each bite. Surface cooling of the ingot not only increases the effective die surface area, but also increases the effective bite ratio.

Increased penetration of work due to surface cooling of an ingot prior to forging was evident in plane strain analyses of radial forging. Figure 10 shows how cooling an ingot originally at a uniform temperature throughout led to increased levels of strain within the cross section of the ingot. The more rigid outer portions of the ingots having cooler surfaces than interiors enhanced the transfer of the forces of the draft to the interior of the ingot. In axisymmetric radial forging simulations using longitudinal sections, penetration of work was also enhanced and the profile of the end of ingot near die became flatter (less sigmoidal) when the ingot was surface-cooled prior to forging. These trends were similar to those observed for increasing bite ratio (Figure 9).

\section{$\underline{\text { Conclusions }}$}

Plane strain simulations using transverse sections are most suitable for studying open die forging. Plane strain simulations using longitudinal sections are not suitable, geometrically, for modeling open die forging, as it is really a section of an infinite slab that is being modeled. Open die forging simulations using Deform showed that the interior of the ingot is most heavily worked. 
Axisymmetric simulations using longitudinal sections were found to be most suitable for studying radial forging. This type of simulation allowed the modeling of elongation effects over the course of a number of bites or passes, and facilitated the study of varying bite ratios, die shapes, friction factors, and boundary conditions. All other factors held fixed, a change in the friction factor did not greatly affect the shape of the deformed ingot or the stress, strain, and strain rate contours for low bite ratios. For larger bite ratios, increasing the friction factor caused slightly better penetration of work into the core of the ingot. Changing the boundary condition on the free end of the ingot affected both the ingot end shape and material flow. Surface cooling prior to forging smoothed out the curvature of the ingot near the die and enhanced penetration of work. Higher bite ratios also led to a less sigmoidal shape for the end of the ingot nearer to the die than did lower bite ratios.

\section{Acknowledgement}

The authors wish to acknowledge the support of this work by the United States Air Force under contract number F33657-88-C-2101.

\section{$\underline{\text { References }}$}

1. COMFORGE Users' Manual, SMS Hasenclever, Dusseldorf, West Germany, 1990.

2. F.R. Dax, H. Henein, I.A.E. Hulthage, and S.E. Morrison, "Billet Sequencing of Open Die Forging of Alloy 718", Materials Processing in the Computer Age, ed. E.R. Voller, M.S. Stachowicz, and B.G. Thomas (Proceedings of an International Symposium Sponsored by TMS Synthesis and Analysis in Materials Processing Committee, New Orleans, La, February 17-21, 1991).

3. DEFORM System Primer, Version 1.1, January, 1990, Battelle Columbus Division, Columbus, Oh.

4. V.K. Jain, "Determination of Heat Transfer Coefficient for Forging Applications", Journal of Material Shaping Technology, 8, (3)(1990), 193 - 202.

5. V.K. Jain, "High Temperature Materials Forging Database" (Emtec Quarterly Status Report, July 1, 1990 to September 30, 1990).

6. S. Kobayashi, S. Oh, and T. Altan, Metal Forming and the Finite Element Method (New York, New York: Oxford University Press, 1989), 30 -33.

7. R. Srinivasan, Wright State University, private communications with authors, 1990.

8. P. Nieschwitz, SMS Hasenclever, private communication with authors, September, 1990.

9. A. Jay, S.R. Lionberger, and A.D. Fine, "Finite Element Metal-Forming Analysis: Two Approaches" (Paper presented at the ASME/ PV and P Conference, Chicago, Illinois, July 20 to 24,1986 ).

10. K. Neu, Cytemp Specialty Steel, private communication with authors, March, 1990.

11. R. Kopp and P. Nieschwitz, "Beitrag zur Qualitatsoptimierung Beim Freifonnschmieden", Archives of Metallurgy, 33 (2)(1988), 247 - 266. 


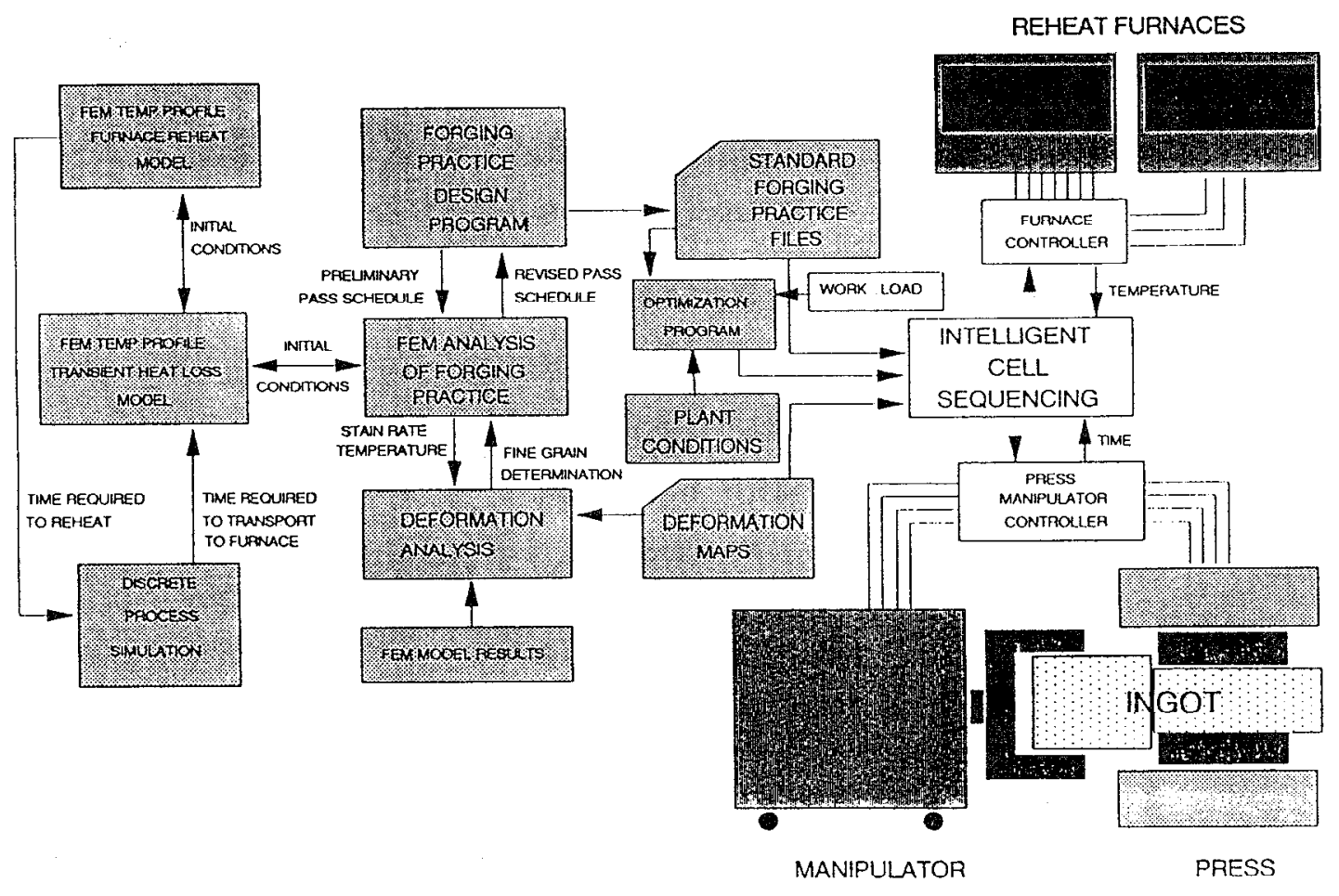

Figure 1: Cytemp's intelligent forging cell. 


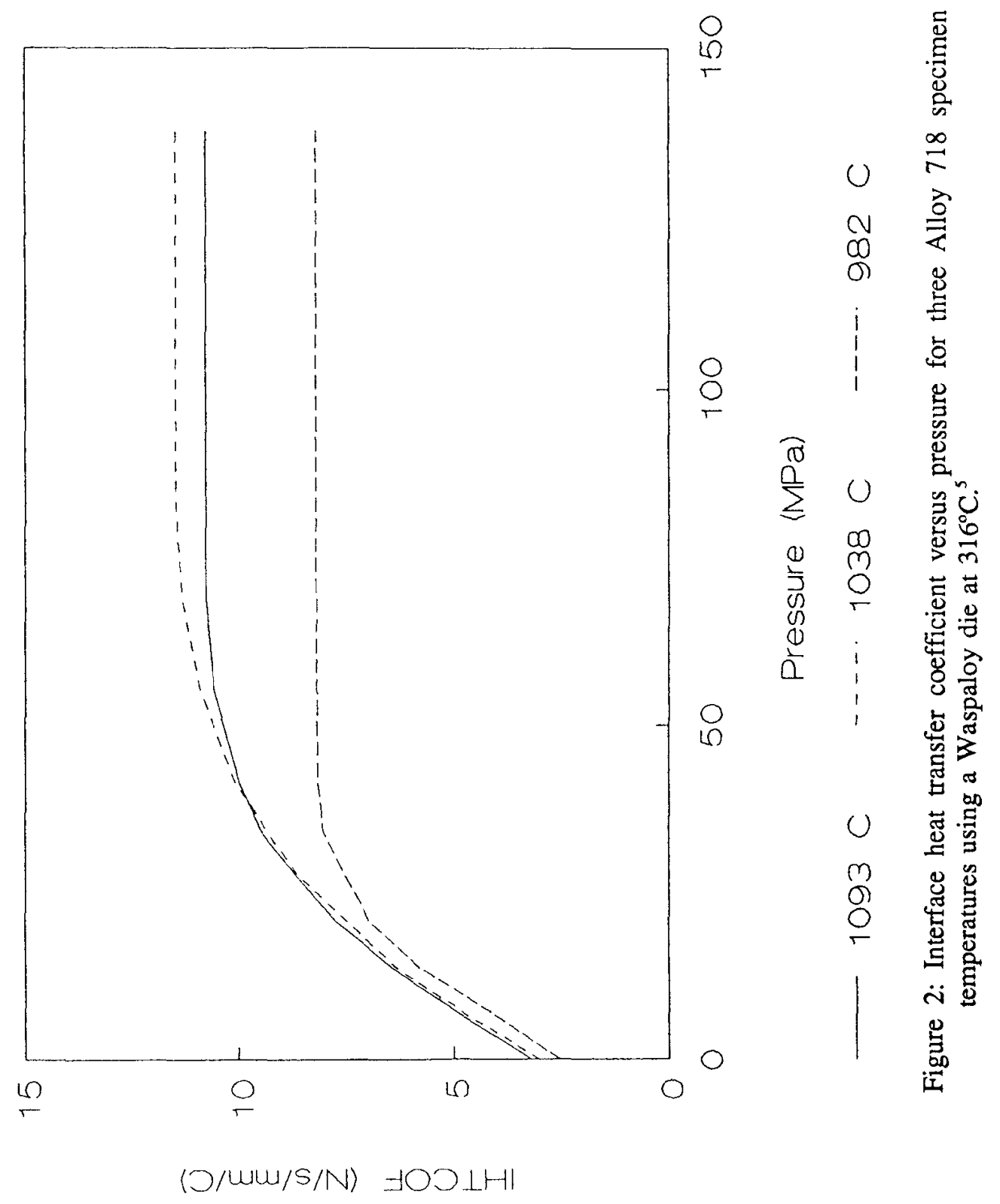




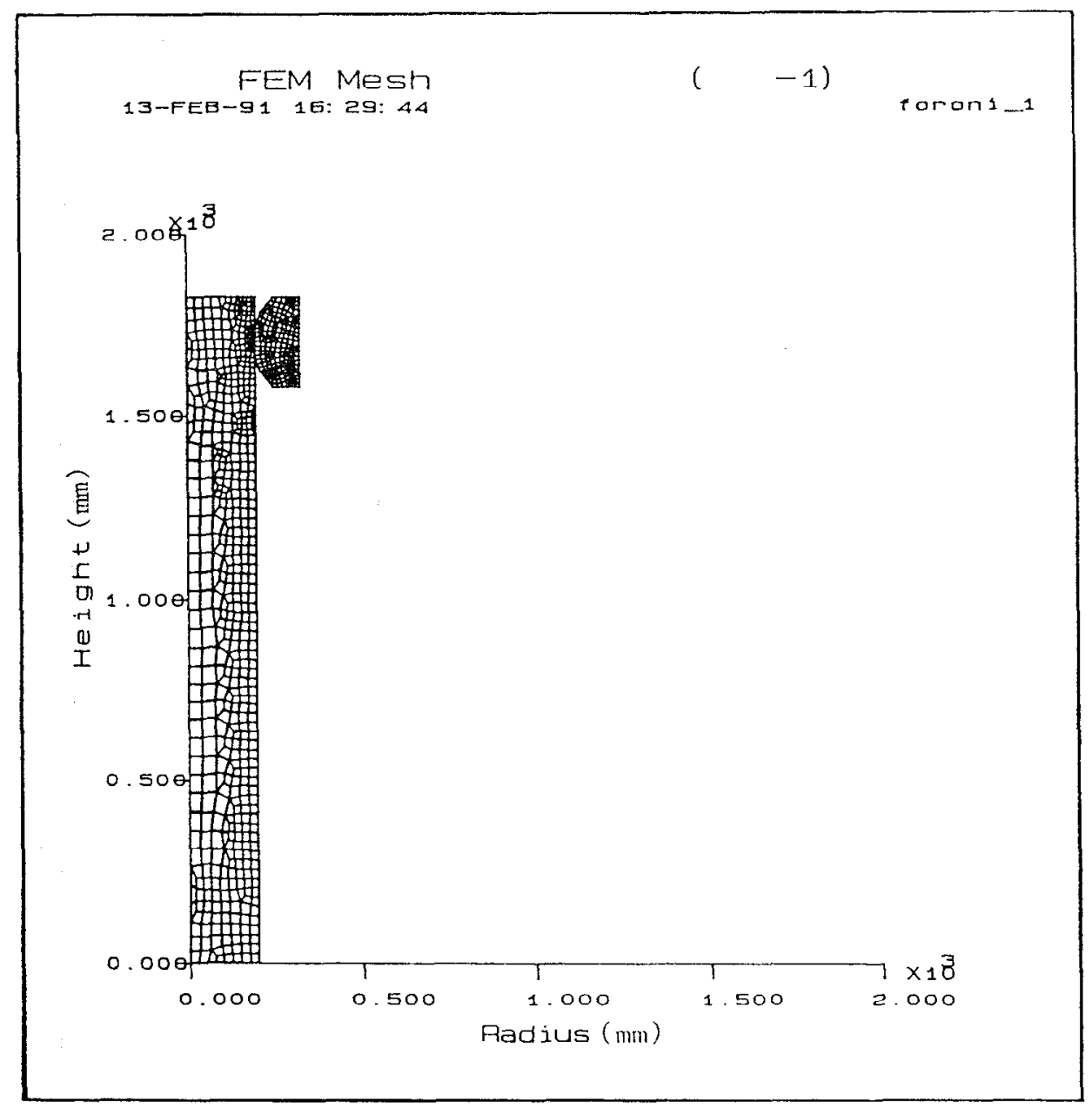

Figure 3. Finite element mesh for simulation of radial forging. The workpiece is $1.8 \mathrm{~mm}$ (72 inches) long; the temperature of the workpiece is $1052^{\circ} \mathrm{C}$. 

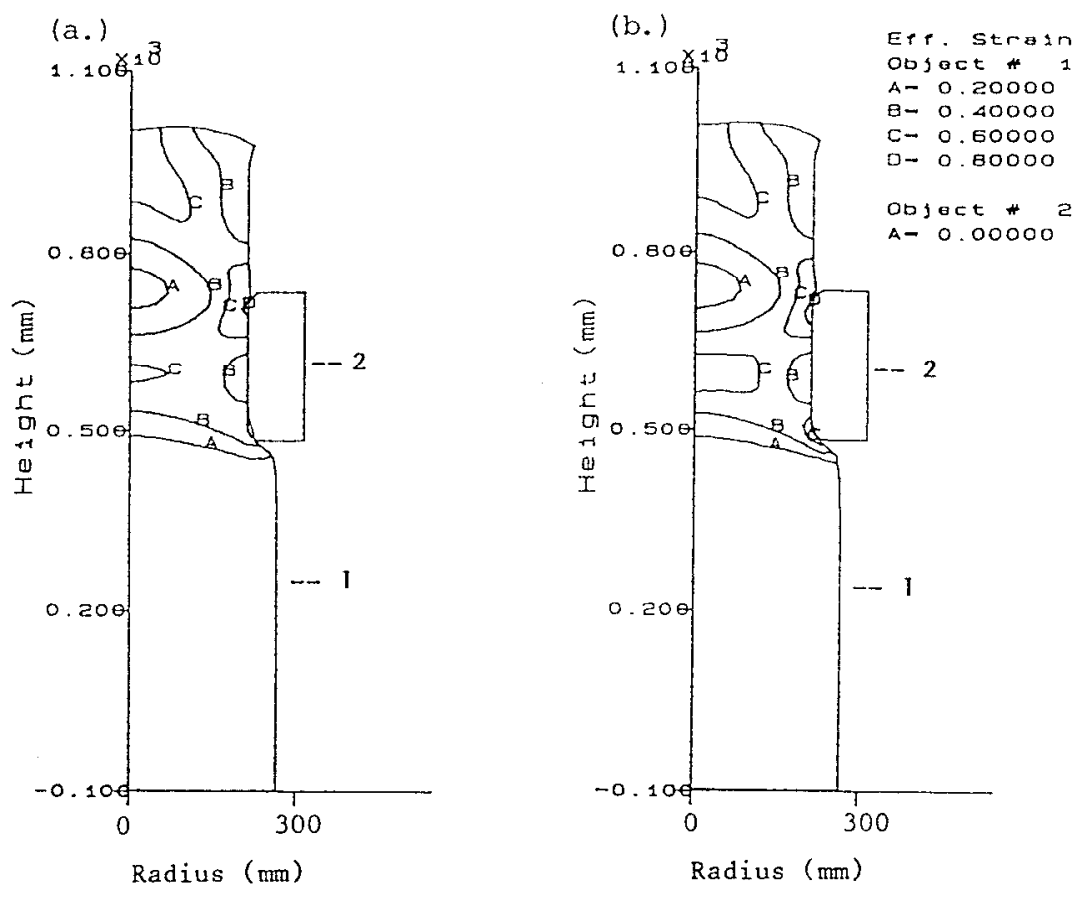

Figure 5. The effect of friction factor on effective strain rate for the second bite of the first pass of radial forging. A $0.25 \mathrm{~m}$ (10 inch) long die was used. (a.) Friction factor, $\mathrm{m}=0.3$. (b.) Fr iction factor, $\mathrm{m}=0.8$.
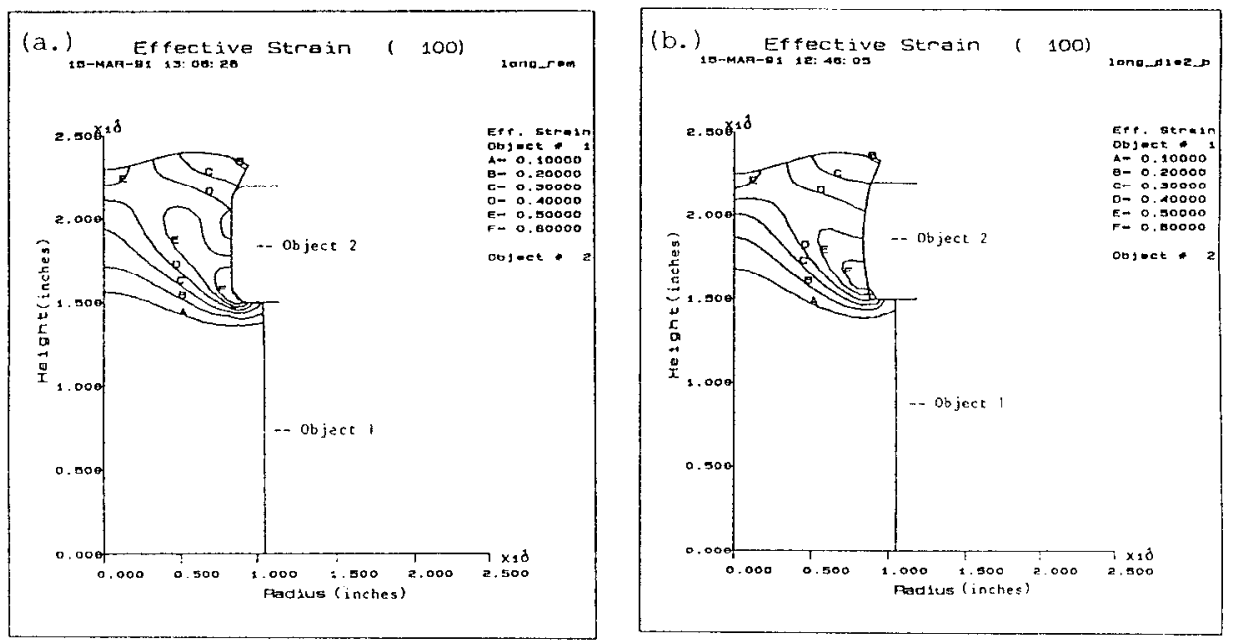

Figure 4. The effect of die shape on cffective stress for the first bitc of the first pass of radial forging. The starting position of the die overhangs the top of the ingot by $76 \mathrm{~mm} \mathrm{(3}$ inches). (a.) Rounded die. (b.) Faceted die. 


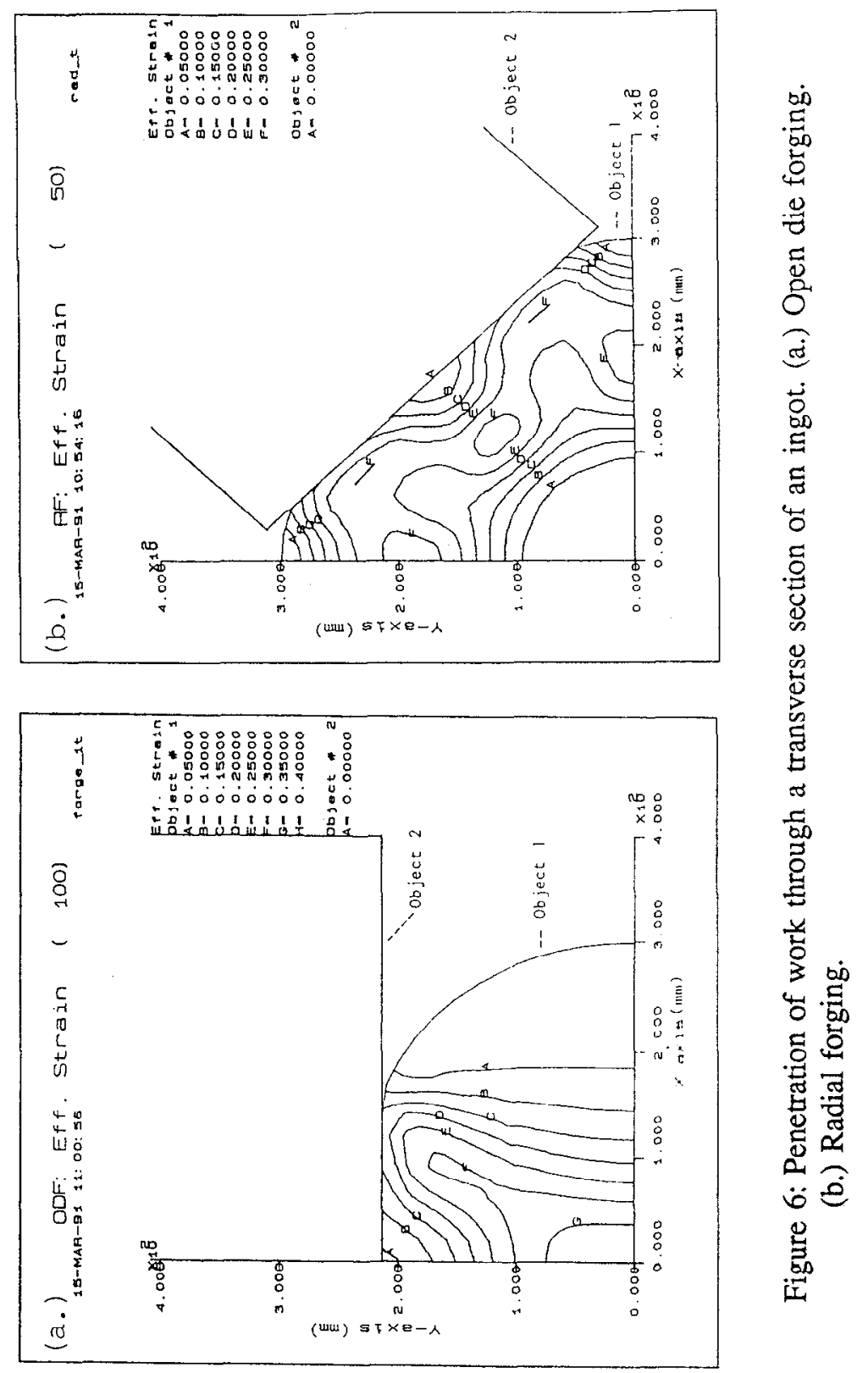



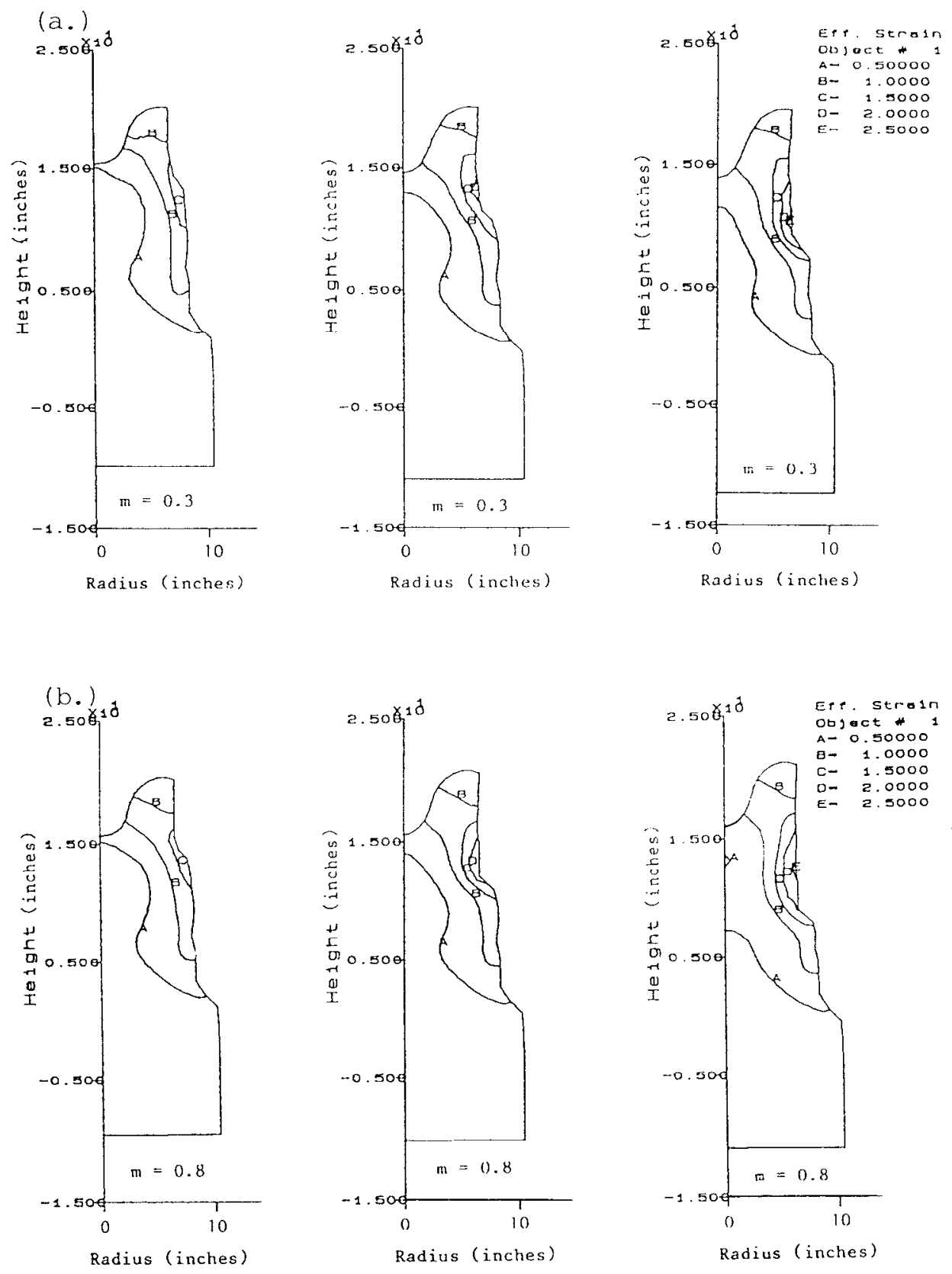

Figure 7. The effect of friction factor on effective strain for three consecutive bites of radial forging. (a.) Friction factor, $m=0.3$. (b.) Friction factor, $m=0.8$. 


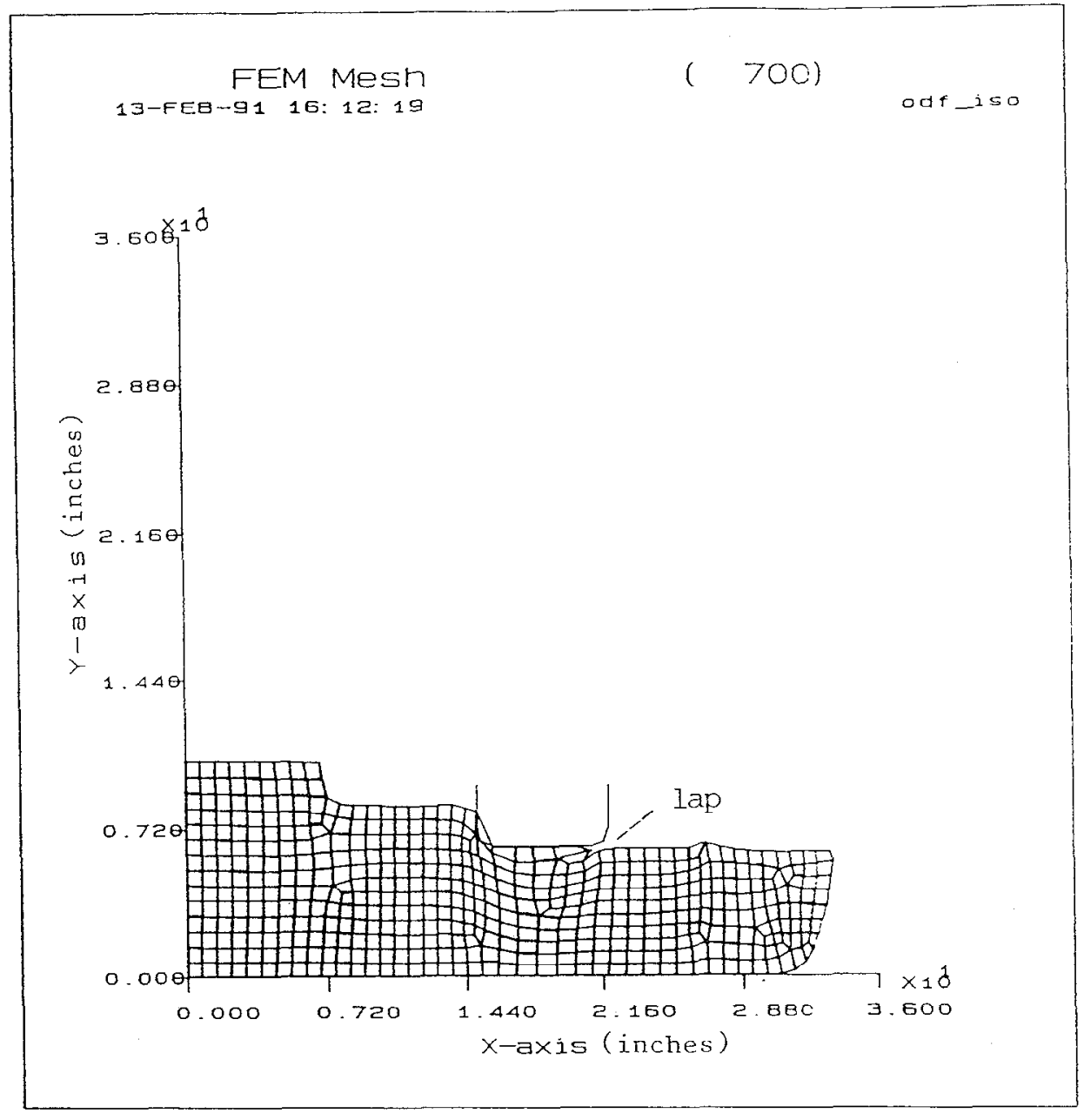

Figure 8. Isothermal open die forging simulation using a longitudinal section of the ingot. This plot shows the position of the die and the shape of the deformed workpiece at the end of the third bite of the second pass. Note the "lap" beneath the trailing edge of the die. 

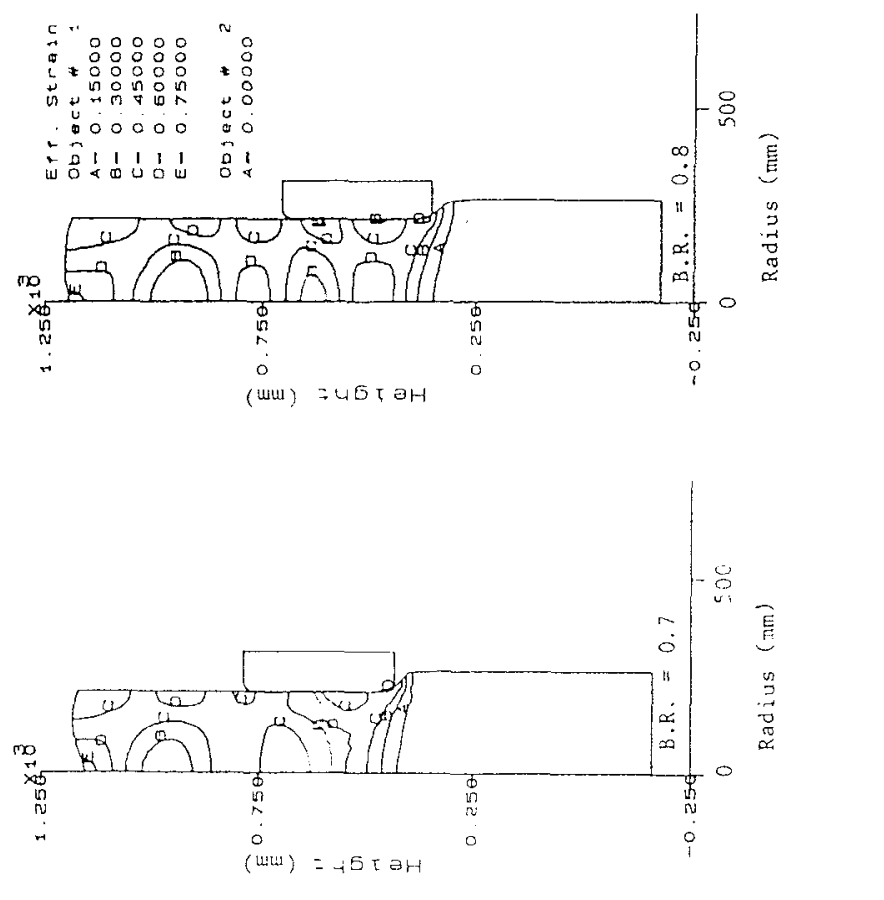

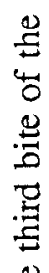

过

宫

点

突 임

. 듬

훕 으

$\$$ ?

.

总

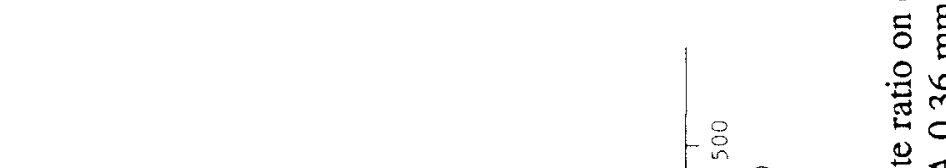

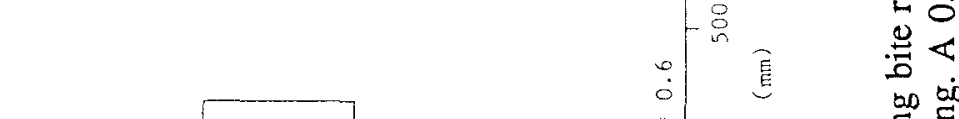
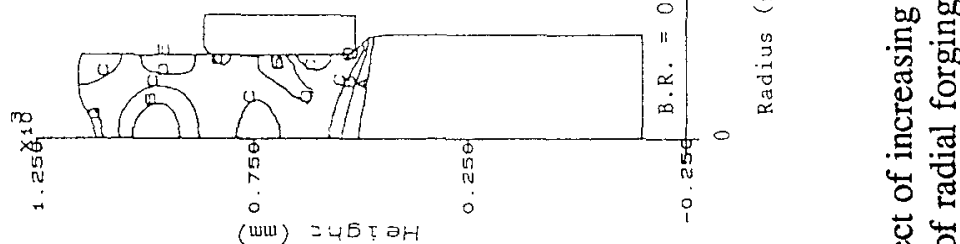

(wய) =45\% పH

पु

出娄

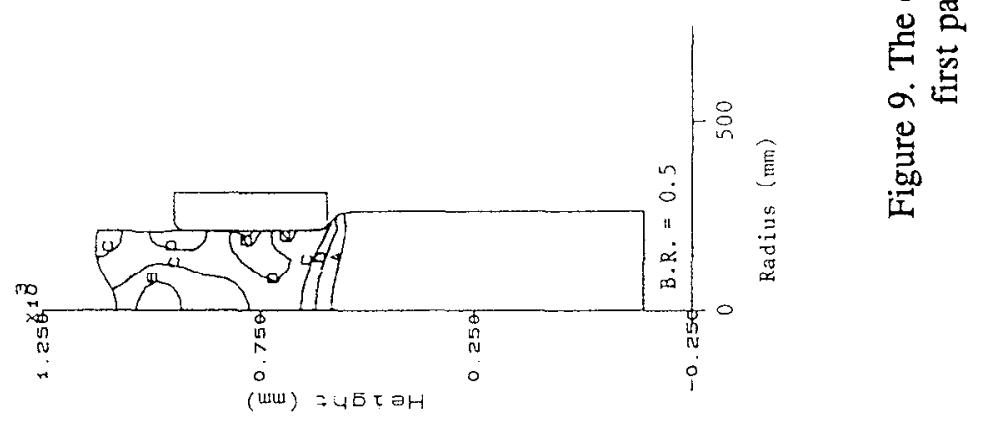



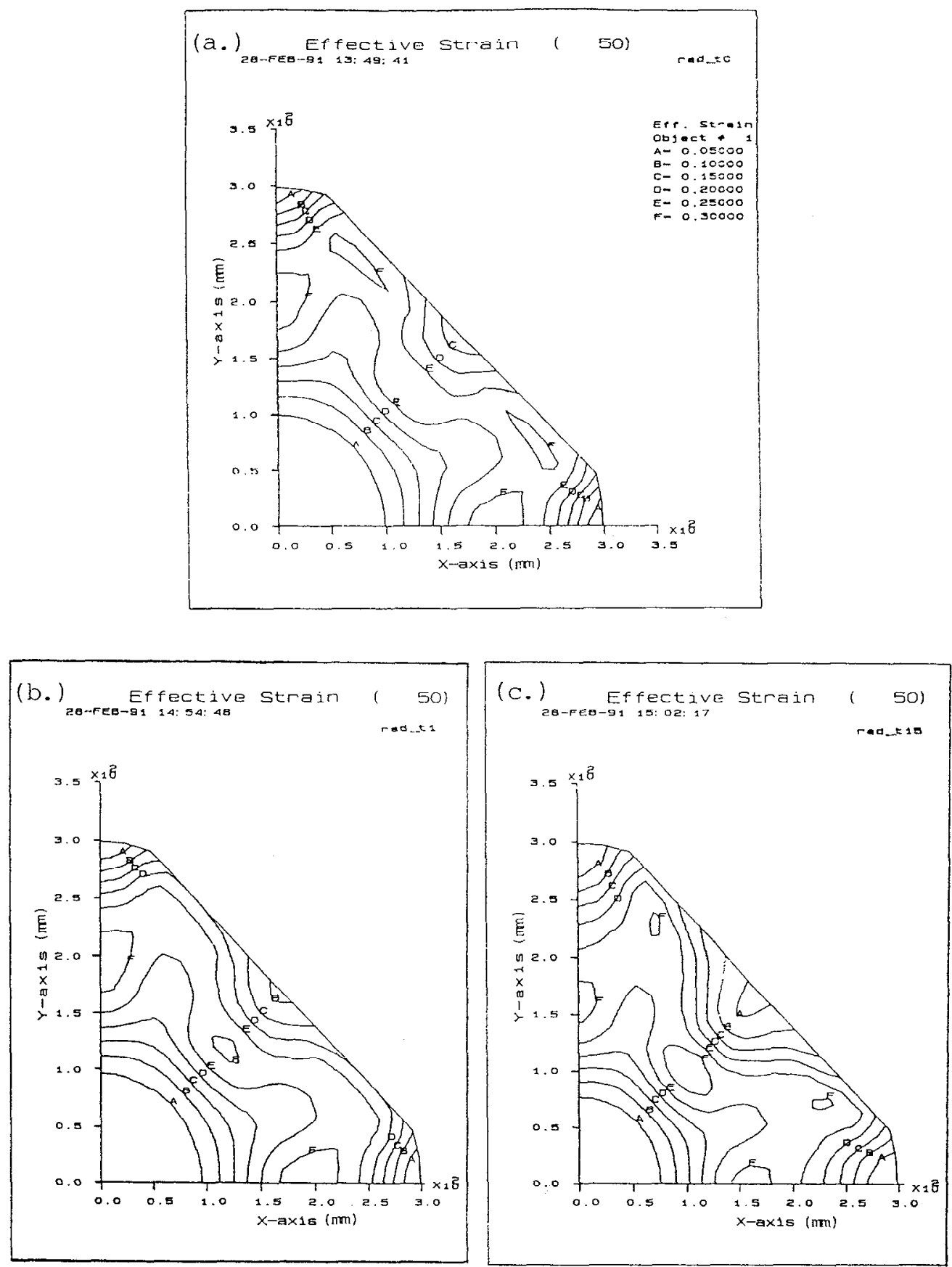

Figure 10: Radial forging simulation on a transverse section of an ingot. (a.) Ingot at a uniform temperature of $1107^{\circ} \mathrm{C}\left(2025^{\circ} \mathrm{F}\right)$ at the start of forging. (b.) Ingot cooled in air for 60 seconds prior to forging. (c.) Ingot cooled in air for 15 minutes prior to forging. 